confirmable or open invitation, only $20(4 \%)$ defaulted. This differential wastage made fixed invitations nearly $20 \%$ more expensive than confirmable or open invitations. As screening services expand such costings will become more relevant. We know of no previous published work that estimates the cost of screening by allowing for differential response rates.

Bone density screening takes nearly 30 minutes and therefore requires scheduled appointments; late attenders are rare but disruptive. Deliberate overbooking would cause lengthy queues, which might be poorly tolerated by both patients and health authorities.

We detected no significant difference in social class among those who attended for a scan in response to the three methods of invitation and returned the postal questionnaire. As the social class of attenders was similar to that of the target population none of the invitation methods seemed to introduce a social class bias.

In conclusion, letters offering fixed appointments that require confirmation seem to combine acceptable response rates and efficient use of resources provided that unconfirmed appointments can be reassigned at short notice. A mixed strategy offering an open appointment as an initial invitation and a fixed appointment requiring telephoned confirmation as a reminder, might ensure the best use of human and materia resources while achieving an acceptable response rate. This hypothesis should be tested in a controlled study.

We thank Dr Susan McPhee, Professor Elizabeth Russell, the staff of the Grampian Health Board Medical Computing Centre, Mr Arthur Fernley of Grampian Regional Council, and an anonymous statistical referee. MJG and DJT were funded by a grant from the Wolfson Foundation. CD and ITR were supported by the chief scientist office of the Scottish Office Home and Health Department. DMR thanks the
Arthritis and Rheumatism Council for continued support. The views expressed here are not necessarily those of the funding bodies.

1 Pierce MS, Lundy S, Palanisamy A, Winning S, King J. Prospective randomised controlled trial of mats of call and recall for cervica cytology screening. BMF 1989;299:160-2.

2 Turnbull D, Irwig L, Adelson P. A randomised trial of invitations to attend for screening mammography. Australian fournal of Public Health 1991;15:33-6.

3 Department of Health Advisory Committee. Consolidated guidance on breast cancer screening. Oxford: Screening Publications, 1990:7.

4 Houghton BA. Response to cervical screening, a survey of tested and untested women in one Buckinghamshire practice. Medical Officer 1968;120:334-7.

5 George WD, Gleave EN, England PC, Wilson MC, Sellwood RA, Asbury D, et al. Screening for breast cancer. BMf 1976;ii:858-60.

6 Hobbs P, Smith A, George WD, Sellwood RA. Acceptors and rejectors of an invitation to undergo breast screening compared with those who referred themselves. I Epidemiol Community Health 1980;34: 19-22.

7 Editorial Committee of the Cardiff Cervical Cytology Study. The Cardiff cervical cytology study; enumeration and definition of population and initial

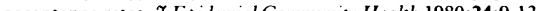

8 Ridsdale LL. Cervical screening in general practice: call and recall. $\mathcal{J} R$ Coll Gen Pract 1987:37:257-9.

9 Spenser JT. A survey of cervical smear screening in general practice. Practitioner 1967:198:274-80.

10 Robertso' AJ, Reid GS, Stoker CA, Bisset C, Waugh N, Fenton I, et al. Evaluation of a call programme for cervical cytology screening in women aged 50-60 years. $B M \mathcal{F} 1989 ; 299: 163-6$.

11 Hobbs P, Kay C, Friedman EHI, St Leger AS, Lambert C, Boggis CRM, et al. Response by women aged 65-79 to invitation for screening for breast cancer by mammography: a pilot study. BMF 1990;301:1314-6.

12 Wilson A, Leeming A. Cervical cytology screening: a comparison of two call systems. BMf 1987;295:181-2.

13 Williams EMI, Vessey MP. Randomised trial of two strategies offering women mobile screening for breast cancer. $B M \mathcal{F} 1989 ; 299: 158-9$.

14 Irwig L, Turnbull D, McMurchie $M$. A randomised trial of genera practitioner-written invitations to encourage attendance at screening mammography. Community Health Stud 1990;14:357-64.

15 Roworth MA. Jones IG. The community health index-How accurate is it? Community Med 1988;10:327-30.

16 Moser CA, Kalton G. Survey methods in social investigation. Aldershot: Gower, 1971:85-90.

17 Office of Population Censuses and Surveys. Classification of occupations. London: HMSO, 1980.

18 General Register Office. Population census small area statistics. Edinburgh General Register Office, 1981

19 Gardner MJ, Altman DG. Statistics with confidence. London: British Medica Journal, 1990:28-33.

(Accepted 6 May 1992)

\title{
Mild and moderate dyskaryosis: can women be selected for colposcopy on the basis of social criteria?
}

Harris Birthright Research Centre, Aberdeen Royal Infirmary, Foresterhill, Aberdeen AB9 2ZB

David J Anderson, research fellow

Grainne M Flannelly, research fellow

Henry C Kitchener, consultant gynaecologist

reter M Fisher, consultant gynaecologist

Evelyn M Mann, consultant cytopathologist

Marion K Campbell, medical statistician

Allan Templeton, professor of obstetrics and gynaecology

Correspondence to: Dr Kitchener.

$B M \Im$ 1992;305:84-7

\author{
David J Anderson, Grainne M Flannelly, Henry C Kitchener, Peter M Fisher, Evelyn M Mann, \\ Marion K Campbell, Allan Templeton
}

\section{Abstract}

Objective-To describe the distribution of cervical intraepithelial neoplasia grades among women with mild and moderate dyskaryosis after a single cervical smear and to determine whether social criteria could help identify women who are at increased risk of grade II or III disease.

Design-Cross sectional analysis within a randomised prospective study. Subjects had a repeat smear, a colposcopic examination, and an excision biopsy of the transformation zone. In addition, women were asked to complete a social questionnaire.

Setting-Colposcopy clinic, Aberdeen.

Subjects-228 women with a single smear test showing mild or moderate dyskaryosis.

Main outcome measures-Histology, age, sexual and contraceptive history, cigarette smoking.

Results-159 (70\%) women had cervical intraepithelial neoplasia grades II or III. Among current smokers the prevalence of grade II and III disease was higher in women who smoked $\geqslant 20$ cigarettes a day $(84 \%)$ than among those who smoked less $(66 \%$; $\mathbf{p}<0.04)$. Women with more than one sexual partner also had a higher prevalence $(75 \%)$ than women with only one partner $(50 \% ; p=0 \cdot 0028)$. Use of oral contraceptives and younger age were not significantly associated. The prevalence of grade II or III disease was up to $66 \%$ in the lower risk groups.

Conclusions-Because of the high prevalence of cervical intraepithelial neoplasia grades II and III in both the high and the low risk groups social factors are not useful for selecting women with mild or moderate dyskaryosis for either early referral to colposcopy or cytological surveillance.

\section{Introduction}

It is generally agreed that women with severe dyskaryosis require colposcopy and cervical biopsy. Noclear consensus exists, however, on the management of mild and moderate dyskaryosis, which are detected 10 times more commonly than severe dyskaryosis. Two contrasting policies exist. The more conservative approach, cytological surveillance with referral to colposcopy only if the abnormality persists over 12-18 months, is based on the belief that a significan proportion of these cytological abnormalities revert to normal with time.

Cervical smears, however, often underestimate the severity of the underlying cervical lesions, with $15-50 \%$ of women with mild and moderate dyskaryosis having 
cervical intraepithelial neoplasia grade III. ${ }^{14}$ These data suggest that any degree of dyskaryosis found on a single smear test justifies immediate referral for colposcopy. Those arguing in favour of this policy point to avoidance of default and the prompt histological diagnosis. Patient anxiety may also be reduced by rapid treatment of an underlying lesion with an early return to normal smear test results. ${ }^{5}$ A survey by the British Society of Colposcopy and Cervical Pathology showed that most pathology units favoured this policy. ${ }^{6}$ However, this approach increases the burden on available services ${ }^{7}$ and risks both overtreatment and increased psychological morbidity for some women. ${ }^{8}$ Previous studies on the natural course of mild and moderate dyskaryosis have been hampered by methodological problems, ${ }^{10}$ particularly retrospective design, inadequate duration of surveillance, unrepresentative populations, and an absence of adequate baseline histological data. In addition, the psychological effects in women of cytological surveillance and referral to colposcopy have not been sufficiently studied to be able to assume that a liberal referral policy would be more reassuring.

The Aberdeen Birthright prospective study is currently investigating the behaviour of mild and moderate dyskaryosis with a view to determining rational management protocols for women with such abnormalities. We report here cross sectional data that correlate the cytological, histological, and sociological characteristics of the study population and examine whether social risk factors could select women for whom immediate colposcopy would be most appropriate.

\section{Patients and methods}

Since August 1989 women with mild or moderate dyskaryosis found on a single cervical smear (the index smear) have been seen at a dedicated colposcopy clinic. Women with previous cytological abnormalities were excluded from the study. The aim was to recruit 1000 women and to allocate them in a randomised fashion into four groups. These comprised an immediate diagnosis and treatment group and three groups with

TABLE I-Histological diagnosis in 228 women with mild or moderate dyskaryosis who had cervical biopsy

\begin{tabular}{|c|c|c|c|c|}
\hline \multirow[b]{2}{*}{ Histology } & \multicolumn{4}{|c|}{ Index smear } \\
\hline & $\begin{array}{c}\text { No of } \\
\text { women }\end{array}$ & $\begin{array}{l}\text { No (\%) with } \\
\text { Mild dyskaryosis } \\
(n=146)\end{array}$ & $\begin{array}{c}\text { No (\%) with } \\
\text { moderate } \\
\text { dyskaryosis } \\
(\mathrm{n}=82)\end{array}$ & $\mathrm{p}$ Value \\
\hline Negative & 15 & $10(7)$ & $5(6)$ & NS \\
\hline Viral change & 22 & $15(10)$ & $7(9)$ & NS \\
\hline \multicolumn{5}{|c|}{ Cervical intraepithelial neoplasia: } \\
\hline Grade I & 32 & $22(15)$ & $10(12)$ & NS \\
\hline Grade II & 52 & $34(23)$ & $18(22)$ & NS \\
\hline Grade III & 107 & $65(45)$ & $42(51)$ & NS \\
\hline
\end{tabular}

TABLE II - Association between cigarette smoking and cervical histology

\begin{tabular}{|c|c|c|c|c|}
\hline & \multirow[b]{2}{*}{$\begin{array}{c}\text { No of } \\
\text { women }\end{array}$} & \multicolumn{2}{|c|}{ No (\%) with histological results } & \multirow[b]{2}{*}{ p Value } \\
\hline & & $\begin{array}{l}\text { Negative viral change or } \\
\text { cervical intraepithelial } \\
\text { neoplasia grade I }\end{array}$ & $\begin{array}{l}\text { Cervical intraepithelial } \\
\text { neoplasia grade II or III }\end{array}$ & \\
\hline \multicolumn{5}{|l|}{ Smoking status: } \\
\hline Never & 67 & $21(31)$ & $46(69)$ & \\
\hline Former smoker & 16 & $8(50)$ & $8(50)$ & NS \\
\hline Current smoker & 104 & $27(26)$ & $77(74)$ & \\
\hline \multicolumn{5}{|c|}{ Current consumption (cigarettes/day): } \\
\hline$<20$ & 55 & $19(34)$ & $36(66)$ & 0.04 \\
\hline$\geqslant 20$ & 49 & $8(16)$ & $41(84)$ & \\
\hline \multicolumn{5}{|c|}{ Current smoker (pack years): } \\
\hline$<4$ & 24 & $7(29)$ & $17(71)$ & \\
\hline $4-8$ & 23 & $6(26)$ & $17(74)$ & NS \\
\hline$\geqslant 8$ & 57 & $14(25)$ & $43(75)$ & \\
\hline
\end{tabular}

^Comparing prevalence of cervical intraepithelial neoplasia grades II and III among groups. six monthly cytological and colposcopic surveillance for 6,12 , and 24 months respectively, after which a histological diagnosis was made. Informed consent was obtained.

The data reported here are cross sectional and derived exclusively from women allocated to immediate diagnosis and treatment. These women had a repeat smear and a colposcopic examination and a large loop excision of the transformation zone, with a directed punch biopsy being taken first if a distinct lesion was seen. If the upper limit of the transformation zone could not be visualised laser cone biopsy was performed. The more severe abnormality reported from either the punch biopsy or the large loop excision was used in the analyses of histology.

All of the women were asked, during an interview with the colposcopist, to complete a questionnaire to document age, smoking, contraception, and sexual indices including the age at first intercourse and the number of sexual partners. Statistical analysis of the data was carried out with the $\chi^{2}$ test for association and logistic regression for multivariate analysis.

\section{Results}

The study began in August 1989 and recruitment was closed by October 1991 . We recruited 913 women, of whom 228 had been randomised to the immediate treatment group. The index smear showed mild dyskaryosis in $146(64 \%)$ women and moderate dyskaryosis in $82(36 \%)$. These proportions did not differ from those in the total study population: 629 $(69 \%)$ women had mild dyskaryosis and $284(31 \%)$ had moderate dyskaryosis $(\mathrm{p}=0 \cdot 16)$.

Table I shows the histological results correlated with the results of the index smear. Of the 228 women, 159 had cervical intraepithelial neoplasia grade II or III. There were no cases of invasive or microinvasive neoplasia. There was no difference between those who presented with mild dyskaryosis and those who presented with moderate dyskaryosis for all grades of pathology ( $p>0.05)$. When the results of colposcopically directed punch biopsy and large loop excision were compared the same abnormality was detected in 92 of 167 cases (55\%). A less severe abnormality was found with the punch biopsy in 59 cases $(35 \%)$ and a more severe abnormality in $16(10 \%)$.

The repeat smear was unsatisfactory in 11 women and could be compared with the index smear in 217 cases. The results agreed in 67 cases (31\%); the abnormality reported with the repeat smear was more severe in 62 cases (29\%) and less severe in $88(40 \%)$. Cervical intraepithelial neoplasia grade II or III was detected in $51(82 \%)$ women in whom the repeat smear showed a more severe abnormality compared with 44 $(50 \%)$ in whom repeat smear showed a less severe abnormality $(\mathrm{p}=0.0001)$.

The relation between the histology and basic sociodemographic parameters were examined. Although $188(82 \%)$ women completed the social questionnaire, smoking and contraceptive information was available for only 187 and 186 women respectively. The mean age of the women was 31 (range 18 to 62 ) years; 158 women were aged between 20 and 40 years, 22 were aged less than 20 years, and 48 were 40 years old or over. Of the women aged 40 years or over, $26(54 \%)$ had cervical intraepithelial neoplasia grade II or III compared with $133(74 \%)$ women aged less than $40(p=$ $0 \cdot 01)$.

There was no difference in the prevalence of cervical intraepithelial neoplasia grades II and III when nonsmokers, former smokers, and current smokers were compared (table II). Current smokers who smoked less than 20 cigarettes a day had a lower prevalence of cervical intraepithelial neoplasia grades II and III 
No $(\%)$ with histological results

\begin{tabular}{|c|c|c|c|c|}
\hline & \multirow[b]{2}{*}{$\begin{array}{c}\text { No of } \\
\text { women }\end{array}$} & \multicolumn{2}{|c|}{ No (\%) with histological results } & \multirow[b]{2}{*}{ p Value ${ }^{\star}$} \\
\hline & & $\begin{array}{l}\text { Negative viral change or } \\
\text { cervical intraepithelial } \\
\text { neoplasia grade I }\end{array}$ & $\begin{array}{l}\text { Cervical intraepithelial } \\
\text { neoplasia grade II or III }\end{array}$ & \\
\hline \multicolumn{5}{|c|}{ No of sexual pattners: } \\
\hline 1 & 36 & $18(50)$ & $18(50)$ & \multirow{2}{*}{$<0.005$} \\
\hline$\geqslant 2$ & 150 & $37(25)$ & $113(75)$ & \\
\hline \multicolumn{5}{|c|}{ Age at first sexual intercourse (years): } \\
\hline$<16$ & 48 & $11(23)$ & $37(77)$ & \multirow{3}{*}{ NS } \\
\hline $16-20$ & 122 & $39(32)$ & $83(68)$ & \\
\hline$>20$ & 18 & $6(33)$ & $12(67)$ & \\
\hline \multicolumn{5}{|c|}{ Use of oral contraceptives: } \\
\hline Never & 18 & $8(44)$ & $10(56)$ & \multirow[t]{2}{*}{ NS } \\
\hline Ever & 168 & $47(28)$ & $121(72)$ & \\
\hline \multicolumn{5}{|c|}{ Duration of oral contraceptive use (years): } \\
\hline$<4$ & 67 & $23(34)$ & $44(66)$ & \multirow{2}{*}{ NS } \\
\hline$\geqslant 4$ & 101 & $24(24)$ & $77(76)$ & \\
\hline
\end{tabular}

^Comparing prevalence of cervical intraepithelial neoplasia grades II and III among groups.

$(66 \%)$ than current smokers who smoked 20 cigarettes or more a day $(84 \%)(p=0 \cdot 04)$. The cumulative effect of cigarette smoking was assessed in current smokers by using pack years (the product of daily consumption of packets of 20 cigarettes and the total number of years of smoking) but this did not influence the incidence of cervical intraepithelial neoplasia grades II and III.

Table III shows the data on sexual and contraceptive history. Women with more than one sexual partner had a significantly higher prevalence of grade II and III disease $(75 \%)$ compared with that in women who had had only one partner $(50 \% ; p<0 \cdot 005)$. The age at first intercourse did not affect the prevalence of grade II and III disease. Only $18(10 \%)$ women had never taken oral contraceptives, and there was no difference in the prevalence of grade II and III disease when duration of use was examined.

Because age less than 40 years, current smoking of 20 cigarettes or more per day, and more than one sexual partner seemed to be associated with an increased risk of grade II and III disease in women with a single smear showing mild or moderate dyskaryosis, independent risk factors were sought to eliminate the possibility of confounding variables by stepwise multivariate logistic regression analysis. Of these, the most significant was the number of sexual partners. In current smokers daily smoking of 20 cigarettes or more was also an independent risk factor. The effect of age was reduced below the level of significance when the data were adjusted for the other variables.

\section{Discussion}

The important question of how to manage women with mildly abnormal smear test results $(1-2 \%$ of all those screened) is best answered by prospectively studying the natural course of such abnormalities. This will establish whether cytological surveillance can be both effective and safe. A central aim of the Aberdeen Birthright study currently in progress is to identify prognostic factors that indicate those women in whom regression or progression of a cervical lesion is most likely to occur. Although the most robust framework for this is a longitudinal study, a cross sectional analysis of a representative population is relevant, particularly as cytological surveillance is currently not widely practised.

Though many case controlled studies have examined the general relation between cervical neoplasia and sociodemographic indices," none has specifically examined this relation in a selected population of women with a single smear showing mild or moderate dyskaryosis. By doing this, risk factors can be evaluated as selection criteria to identify those women for whom early referral to colposcopy would be most appropriate.

The histological data have been grouped into the categories of cervical intraepithelial neoplasia grades II or III and grade I or less to distinguish cervical pathology which many would consider of little importance from that which most would advocate treating without delay. The finding of cervical intraepithelial neoplasia grade III in $47 \%$ of patients with mild or moderate dyskaryosis is similar to the findings in recent cross sectional studies. ${ }^{2-4}$ There was no difference in the incidence of grade III disease between patients with a single smear showing mild and moderate dyskaryosis, which justifies the inclusion of women with both degrees of dyskaryosis in our prospective study. The correlation between directed punch biopsy and large loop excision, which showed that the punch biopsy underestimated the lesion in $35 \%$ of cases supports the decision to include excision biopsy of the entire transformation zone in the study protocol. The relation between the repeat smear test result and the histology suggests that repeated smears may improve the cytological representation of the underlying lesion. However, $50 \%$ of the women whose repeat smear showed a less severe abnormality still had cervical intraepithelial neoplasia grade II or III. This will be addressed further in the context of the longitudinal study.

\section{RISK FACTORS}

Current cigarette smoking, which has been shown to increase the risk of both invasive cervical cancer and cervical intraepithelial neoplasia, ${ }^{12}$ was an independent risk factor for grade II and III disease only in women currently smoking 20 or more cigarettes a day. This dose-related effect fits well with the idea that cigarette smoking acts as a promoter in this disease. Our finding that more than one previous sexual partner was associated with a greater prevalence of cervical intraepithelial neoplasia grades II and III is consistent with the well established epidemiological link between sexual characteristics and both invasive and preinvasive cervical intraepithelial neoplasia..$^{13}$ The suggested relation between use of oral contraceptives and an increased risk of invasive and preinvasive cervical neoplasia, ${ }^{15}{ }^{16}$ becomes less clear after adjusting for potential confounding variables. ${ }^{17}$ We did not find that oral contraceptives were associated with an increased incidence of grade II and III disease.

Do these risk factors for an increased prevalence of cervical intraepithelial neoplasia grades II and III in women with mildly abnormal smears have implications for clinical practice? The answer seems to be that they are of limited practical use. High risk groups have been identified in this study-namely, heavy current smokers, those with more than one sexual partner, and those under 40 years. However, the prevalence of cervical intraepithelial neoplasia grades II and III of up to $66 \%$ in the remaining groups of women cannot be considered sufficiently low to justify a selective policy. Furthermore, selecting women for referral for colposcopy on the basis of a sexual history would be fraught with ethical and management problems and could risk increasing the psychosexual trauma associated with an abnormal smear result.

Clearly, there is a need for greater selectivity when deciding which women to refer for colposcopy on the basis of a single smear showing mild or moderate dyskaryosis. Our results suggest that social criteria are not useful in this regard and that population based studies of natural course remain the most reliable means of addressing this important problem.

We thank Birthright for funding this project and Dr Barbara Thompson (department of obstetrics and gynaecology) and Ms Kathleen Swanson (department of cytology) for their help in preparing this paper. We also thank Sister Flora Abramovich for her help in the clinics. 
Jones RW, Yeong ML, Stewart AW, Hitchcock GC, Dervan WE. Cervical cytology in the Aukland region. NZ Med $\mathcal{F} 1988 ; 101: 132-5$

2 Kitchener HC, Burnett RA, Wilson ES, Cordiner JW. Colposcopy in a family planning clinic: a future model. BMF 1987;294:1313-5.

3 Walker EW, Dodgson J, Duncan ID. Does mild atypia on a cervical smea warrant further investigation? Lancet 1986;ii:672-3.

4 Soutter WP, Wisdom S, Brough AK, Monaghan JM. Should patients with mild atypia on a cervical smear be referred for colposcopy? $\mathrm{Br} \mathcal{F}$ Obste Gynaecol 1986;93:70-4.

5 Soutter WP. Referral rates for colposcopy. BMF 1990;301:1335-6.

6 Kitchener H. United Kingdom colposcopy survey, British Society for Colposcopy and Cervical Pathology. Br F Obstet Gynaecol 1991:98:1112-6.

Raffle AE Alden B, MacKenzie EFD. Six years' audit of laboratory workload and rates of referral for colposcopy in a cervical screening programme in and rates of referral for colposcopy in
three districts. $B M \mathcal{F}$ 1990;301:907-11.

8 Campion MJ, Brown JR, McCance DJ, Atia W, Edwards R, Cuzick J,et al. Psychosexual trauma of an abnormal smear. Br J Obstet Gynaecol 1988;95: $175-81$.

9 Robertson JH, Woodend BE, Crozier EH, Hutchinson J. Risk of cervical cancer associated with mild dyskaryosis. BMf 1988;297:18-2

10 Campion MJ, McCance DJ, Cuzick J, Singer A. Progressive potential of mild cervical atypia: prospective cytological, colposcopic and virological study. Lancet 1986;ii:237-40
11 Cusick J, Singer A, De Stavola BL, Chomet J. Case-control study of risk factors for cervical intraepithelial neoplasia in young women. Eur $\mathcal{Y}$ Cancer 1990;26:684-90.

12 Winklestein W, Shilltoe EJ, Brand R, Johnson K. Further comments on cancer of the cervix, smoking and Herpesvirus infection. Am $\mathcal{J}$ Epidemiol 1984;119:1-8.

13 Clarke AE, Hatcher J, Mckeown E, Ysseng E, Lickrush GM. Cervical dysplasia: association with sexual behavior, smoking and oral contraceptive use. Am 7 Obstet Gynecol 1985;151:612-6.

14 Donnan SPB, Wong FWS, Ho SC, Lau EMC, Takashi K, Estévé J, et al. Reproductive and sexual risk factors and human papilloma virus infection in cervical cancer among Hong Kong Chinese. Int f Epidemiol 1989;18:32-6.

15 Vessey MP, Lawless M, McPherson K, Yeates D. Neoplasia of the cervix uter essey MP, Lawless M, McPherson K, Yeates D. Neoplasia of the cervix uter
and contraception: a possible adverse effect of the pill. Lancet 1983;ii:930-4. and contraception: a possible adverse effect of the pill. Lancet 1983;i1:930-4. Brinton LA, Higgins GR, Lehman HF, Mallin K, Savitz DA, Trapido E, et al.
Long term use of oral contraceptives and risk of invasive cancer. Int f Cancer Long term use of

17 Celatnano DD, Klassen AC, Weisman CS, Rosenshein NB. The role of contraceptive use in cervical cancer: The Maryland cervical cancer casecontrol study. Am J Epidemiol 1987; 126:592-604.

(Accepled 8May 1992
Health Care Evaluation

Unit, Department of

Epidemiology and Public

Health Medicine,

University of Bristol,

Bristol BS8 2PR

Joanna Coast, research

assistant in health economics

BMF 1992;305:87-90

\title{
Reprocessing data to form QALYs
}

\author{
Joanna Coast
}

\begin{abstract}
Objectives-To determine whether reprocessing data from published sources into quality adjusted life years (QALYs), as recommended in The $Q A L Y$ Toolkit, is a useful method of helping purchasing authorities to determine the most cost effective pattern of care to buy for their populations.

Setting-United Kingdom.

Design-The method was tested for six elective surgical conditions; data from published studies were reprocessed into the Rosser index, to obtain values for change in quality of life. These were then used to form QALYs. A small validation exercise was carried out.
\end{abstract}

Main outcome measures-QALYs formed from the Rosser index.

Results-Published data could not be found for three interventions (cataract surgery, inguinal hernia repair, varicose vein surgery). For the remainder (prostatectomy, hip replacement, and knee replacement) data were found which could be reprocessed to form QALYs, though it was often hard to compare data from different studies and many assumptions had to be made.

Conclusion-The value of QALY results obtained by this method is questionable, given the large number of assumptions which had to be made. For many interventions published data are unlikely to be available.

\section{Introduction}

The current reorganisation of the National Health Service offers health authorities the opportunity to purchase the pattern of provision that best meets the needs of the populations they serve. The realisation of this potential should, however, be informed by evidence about appropriate levels of provision and priorities. ${ }^{1}$ A lack of such evidence currently clouds decisions and will continue to do so in the near future. As a short term expedient this paper considers the practicalities of drawing on available evidence to inform choices about the balance of care and examines the value of a rapid method of deriving utility values to incorporate into cost effectiveness measures.

\section{Rationale}

Evidence about cost effectiveness is crucial to purchasing decisions. ${ }^{2}$ With such evidence the costs of treating extra patients by particular interventions can be related to the benefits and the total benefit available to patients thus maximised. ${ }^{3}$ One difficulty, however, is in measuring benefit in a comparable manner for different interventions. One method of measuring benefit which aims to solve this problem is that of using utility values, of which the quality adjusted life year (QALY) is one form. ${ }^{34}$

The QALY Toolkit ${ }^{5}$ has been used as a source document for determining utility values. ${ }^{6}$ Although the toolkit does not claim to have validated any of its methods, they have recently become more widely used $^{7.9}$ Three methods are recommended for determining utility values: collecting disability-distress data using a self completed questionnaire (observational studies); eliciting views from selected reference groups; and reprocessing data from published sources. ${ }^{5}$

Observational studies of long term outcomes cannot be a speedy method of informing decisions. Eliciting views from selected reference groups is also inappropriate as no reference group holds all the relevan information; in particular, clinicians may value health states differently from patients ${ }^{7}$ and often have little knowledge of long term outcomes.

To inform purchasing decisions in the short term, therefore, the most appropriate method is to base utility values (QALYs) on reprocessed data from published studies which measured quality of life as assessed by the patient. This method has been used to consider medical care in end stage renal failure, upper limb joint replacement, surgery for scoliosis, and drug treatment for cystic fibrosis. ${ }^{10}$ I selected six common interventions that might be suitable for reprocessing data because they have a circumscribed purpose, the therapeutic technique is stable, and data are likely to be available on outcome: prostatectomy for benign prostatic hypertrophy, cataract surgery, inguinal hernia repair, total joint replacement to treat osteoarthrosis of hip and knee, and varicose vein surgery.

\section{Methods}

The Rosser classification of illness states, or Rosser index, ${ }^{51112}$ was used to form QALYs. This has two dimensions, disability and distress, and 29 possible health states. The index is the most commonly used in the United Kingdom, ${ }^{4710}$ thus making the results of this study comparable with others.

A simplified version of the formula used to calculate QALYs is as follows (the equation given by Gudex et al 